\title{
The Environmental-Endocrine Basis of Gynandromorphism (Intersex) in a Crustacean
}

\author{
Allen W. Olmstead* and Gerald A. LeBlanc \\ Department of Environmental and Molecular Toxicology, North Carolina State University, Raleigh, NC 27695-7633, USA \\ * Current address: US Environmental Protection Agency, Duluth, MN 55804-2595, USA
}

Correspondence to: Gerald A. LeBlanc, PhD, Email: ga_leblanc@ncsu.edu, Phone: (191)515-7404, Fax: (919)515-7169

Received: 2006.10.03; Accepted: 2006.11.30; Published: 2006.12.05

Commensurate with the decline in many crustacean populations has been an accumulation in reports of sexu-
ally ambiguous individuals within these populations. The cause of gynandromorphism or intersex among crus-
taceans is unknown. We show that gynandromorphism in the branchiopod crustacean Daphnia magna is initi-
ated by the sex-determining hormone methyl farnesoate when levels of the hormone are intermediate between
low levels that stimulate the production of broods containing all female offspring and high levels that stimulate
the production of broods of all male offspring. The incidence of hormonally-induced gynandromorphism was
low $(0.14 \%$ at the maximum stimulatory hormone concentrations) but was significantly increased (46-fold)
when the animals were hormone-treated at 30 \% C. Some environmental chemicals also can stimulate the gynan-
dromorphic phenotype as we demonstrated with the insecticide pyriproxyfen. Gynandromorphism occurs due
to inadequate signaling of male-sex determination since: a) gynandromorphs did not occur in a population that
was producing only female offspring; and, b) conditions that stimulated gynandromorphism also reduced the
incidence of male offspring. We suggest that male sex determination normally occurs prior to the first embry-
onic cleavage. Elevated temperature may alter the timing of sex determination such that methyl farnesoate sig-
naling occurs after the first embryonic cleavage and bilateral gynandromorphism occurs as a consequence of
signaling to only one of the daughter cells. These results demonstrate that environmental factors can cause ab-
errant sex determination via perturbations in methyl farnesoate signaling.

Key words: methyl farnesoate, sex determination, gynandromorphism, intersex, terpenoids, juvenoids, pyriproxyfen

\section{Introduction}

Annual harvest records reveal a disturbing and ubiquitous decline in crustacean stocks [1-4] with some economically important crustacean populations having declined by over $90 \%$ in recent years [5]. The status of ecologically important populations that are not harvested for human consumption is largely unknown. Multiple factors likely contribute to crustacean population declines including overharvesting, loss of habitat, pollution, and climate changes [5-7]. Commensurate with this decline has been an apparent increase in reported incidents of sexually ambiguous (gynandromorphic) individuals [8]. Gynandromorphs exhibit both male and female sex characteristics, often with a bilateral division of the characteristics [8]. These developmental aberrants have been noted among the Brianchiopoda, Maxillopoda, and Malacostraca - including the economically important decapods (crabs, lobsters, shrimp, crayfish) [8].

The causes and consequences of gynandromorphism in crustacean populations are unknown. Gynandromorphs may suffer compromised fecundity $[9,10]$, but their incidence in populations seems sufficiently low so as to not impact population sustainability. However, progressive environmental factors (e.g., climate change, pollution) could be contributing to gynandromorphism and the incidence of gynandromorphs could be diagnostic of a decline in environmental quality.

Sex determination of some crustacean species is under the control of environmental cues [11,12]. We
[13] discovered and others [14] have confirmed that the crustacean terpenoid hormone methyl farnesoate is a sex determinant in some branchiopod crustaceans. Thus, an environmental signaling pathway exists, which if perturbed, might result in the production of sexually ambiguous individuals. Suzuki and Nijhout [15] demonstrated that elevated temperatures could alter the juvenoid hormone signaling pathway (homologous to the methyl farnesoate signaling pathway of crustaceans [16,17]), resulting in an altered color phenotype in the insect Manduca sexta. We hypothesized that elevated environmental temperatures or other changing environmental factors might similarly interact with the methyl farnesoate signaling pathway revealing the gynandromorphic phenotype in crustaceans.

In the present study we have tested this hypothesis with three specific goals: 1 ) assess the ability of methyl farnesoate to stimulate the production of gynandromorphic daphnids (Daphnia magna, Cladocera, Branchiopoda, Crustacea); 2) investigate the roles of elevated environmental temperature in the expression of this phenotype; and, 3) determine whether some environmental pollutants might stimulate the appearance of this abnormal phenotype.

\section{Materials and Methods}

\section{Daphnids}

Cultures of Daphnia magna have been maintained in this laboratory for over 15 years and were initiated with animals from the US Environmental 
Protection Agency, Mid-Continent Ecology Division Laboratory in Duluth, MN, USA. Culture conditions have been described previously [18]. Medium used in culturing and all experiments was prepared with deionized water reconstituted with $192 \mathrm{mg} / 1$ $\mathrm{CaSO}_{4} \cdot \mathrm{H}_{2} \mathrm{O}, 192 \mathrm{mg} / 1 \mathrm{NaHCO}_{3}, 120 \mathrm{mg} / 1 \mathrm{MgSO}_{4}, 8.0$ $\mathrm{mg} / 1 \mathrm{KCl}, 1.0 \mu \mathrm{g} / 1$ selenium, and $1.0 \mu \mathrm{g} / 1$ vitamin $B_{12}$ Cultures were maintained in 11 beakers at concentrations of 40 daphnids per liter and were housed in upright incubators at $20^{\circ} \mathrm{C}$ and $16: 8 \mathrm{~h}$ light:dark photoperiod. Medium was changed three times weekly with daphnids raised for three weeks. Food was provided in the form of the green algae, Pseudokirchneriella subcapitata, and a fish food homogenate. Algae was cultured in Bold's Basal medium [19] at room temperature. Fish food homogenate was prepared by processing $10 \mathrm{~g}$ of Tetrafin ${ }^{\circledR}$ Goldfish Flakes (Pet International, Chester Hill, New South Wales, Australia) in a blender for 10 minutes. Solids were settled overnight and the supernatant was decanted off and used in feeding. Daphnid cultures were provided $1.4 \times 10^{8}$ cells algae and $4 \mathrm{mg}$ (dry weight) fish food twice daily. These culture conditions maintain the daphnids in the parthenogenetic (asexual) reproductive stage with the production of all-female broods of offspring.

\section{Gynandromorphism incidence}

The normal incidence of gynandromorphism among asexually-reproducing daphnids was evaluated in broods released from 150 maternal organisms reared under standard culture conditions, except that individual animals were maintained in $50 \mathrm{ml}$ beakers containing $40 \mathrm{ml}$ media. Individual offspring from each brood of organisms were sexed. Male neonates were determined by the presence of two elongated first antennae and female sex was determined by the presence of two rudimentary first antennae [20]. Neonatal intersex animals were identified by the presence of one elongated and one short first antenna. As adults, these animals exhibited intersex characteristics as described in the Results section. Each maternal daphnid was provided algae $\left(7.0 \times 10^{6}\right.$ cells $)$ and fish food homogenate ( $0.2 \mathrm{mg}$ dry weight) twice daily. The offspring from only a single brood per maternal daphnid was evaluated.

Intersex incidence also was evaluated among daphnids that were entering a cycle of sexual reproduction and thus were producing both male and female offspring. For these experiments, maternal daphnids were exposed to various terpenoid, phenoxyphenoxy, and steroid compounds in an effort to stimulate the production of male offspring. Treatments are described in Table 1. During these experiments, daphnids were treated with the chemicals for 24 hours prior to molting (see [13] for definitive protocol). This window of exposure covers a critical period during which methyl farnesoate determines the sex of the resulting daphnids $[13,21]$. Those offspring exposed in ovo were then sexed - as male, female, or gynandromorphic- after release from the maternal brood chamber. Treatment success in the stimulation of male sex determination among offspring is summarized elsewhere [22].
Table 1 Chemicals and exposure concentrations used to stimulate the production of broods containing varying percentages of male offspring. Results from controls used in these experiments (no chemical treatment) also were used to establish the normal incidence of gynandromorphism among daphnids producing only female offspring. All of the data were used to assess the relationship between the incidence of gynandromorphic individuals and sex of the brood siblings. Each treatment contained 10 maternal daphnids. Many exposure concentrations were repeated in multiple experiments.

\begin{tabular}{c|c|c|}
\hline Treatment & $\begin{array}{c}\text { Number } \\
\text { of } \\
\text { treat- } \\
\text { ments }\end{array}$ & \multicolumn{1}{|c|}{$\begin{array}{c}\text { Exposure concentration } \\
(\mu \mathrm{g} / \mathrm{l})\end{array}$} \\
\hline Control & 15 & not applicable \\
\hline Methyl farnesoate & 97 & $\begin{array}{l}2.3,3.5,4.6,6.5,8.9,10,12,17, \\
20,22,24,29,34,36,40,42,48, \\
50,60,66,72,77,84,100,129 \\
140,200,400,667,800\end{array}$ \\
\hline Methoprene & 16 & $\begin{array}{l}11,20,36,50,63,100,112,200, \\
360,400\end{array}$ \\
\hline Pyriproxyfen & 23 & $\begin{array}{l}0.019,0.025,0.034,0.050,0.060, \\
0.075,0.10,0.11,0.12,0.15,\end{array}$ \\
\hline Juvenile hormone III & 2 & 20,200 \\
\hline 20-hydroxyecdysone & 2 & $1.0,10$ \\
\hline
\end{tabular}

The relationship between the occurrence of the gynandromorphic phenotype and the average sex ratio of broods in a treatment (Table 1) was assessed by dividing treatments into three categories according to the average percentage of males produced within the brood: 1 ) $<10 \%$ males, 2) $10-90 \%$ males, and 3) $>90 \%$ males. The number of gynandromorphic individuals in each category was determined and analyzed statistically as a chi-square or Fisher's exact analysis of contingency tables to test for differences in gynandromorphic incidents across the three categories [23].

Methyl farnesoate used in these experiments was obtained from Echelon Biosciences (Salt Lake City, UT, USA). Pyriproxyfen and methoprene were obtained from Chem Services (West Chester, PA, USA). 20-Hydroxyecdysone and juvenile hormone III were purchased from Sigma (St. Louis, MO, USA). Methyl farnesoate was delivered to test solution in methanol. All other chemicals were delivered in ethanol. Carrier solvent levels in treatments never exceeded $0.01 \%$.

\section{Hormonal induction of gynandromorphism}

Daphnids were exposed for 24 hours just prior to molting to a range of concentrations of methyl farnesoate or pyriproxyfen as described for previous experiments. All offspring were scored as being male, female, or gynandromorphic. The concentrationresponse curves were fitted to the data using a sigmoidal function with Origin software (OriginLab Corp. Northampton, MA, USA).

Promotion of the gynandromorphic phenotype by elevated temperature

The incidence of gynandromorphic offspring among methyl farnesoate-exposed, pyriproxyfen- 
exposed, and un-exposed maternal daphnids was determined as described above with the following modifications. Daphnids were initially maintained at $20^{\circ} \mathrm{C}$, then transferred a $30^{\circ} \mathrm{C}$ incubator during the 24 hour period of hormone treatment. Daphnids were then returned to hormone-free media and the $20^{\circ} \mathrm{C}$ incubator for the remainder of the experiment. Therefore, these animals were exposed to either methyl farnesoate or pyriproxyfen and elevated temperature during the 24 hour window of sensitivity for sex determination.

\section{Results}

\section{Gynandromorphism among unstimulated daphnids}

The incidence of gynandromorphic offspring born to daphnids reared under conditions that maintained the population in the asexual-reproductive state was evaluated. A total of 8,918 offspring were evaluated for the gynandromorphic phenotype. All offspring exhibited normal female characteristics. Thus, the incidence of spontaneous gynandromorphism within this population of daphnids was $<0.01 \%$.

\section{Hormonal induction of gynandromorphism}

The occurrence of gynandromorphic offspring among females exposed to various concentrations of the male sex-determinant methyl farnesoate was next evaluated. Female daphnids were exposed to methyl farnesoate concentrations ranging from 2.3 to 800 $\mu \mathrm{g} / 1$. Gynandromorphic offspring were produced only among maternal daphnids exposed to $48-50 \mu \mathrm{g} / 1$ methyl farnesoate (Fig. 1A). Interestingly, this level of exposure approximates the level of methyl farnesoate that stimulates a $\sim 50: 50$ sex ratio among offspring [21]. At maturity, gynandromorphic animals exhibited a bilateral gynandromorphic morphology that included one long and one short first antennae and one symmetrical (female-like) and one asymmetrical (malelike) carapace edge (Fig. 2). Sex-intermediate characteristics also were common among mature gynandromorphic individuals. These included a head capsule morphology that was intermediate between the male and female, an abnormally small penis, and a small brood chamber with a dimunitive or distorted abdominal process (see Olmstead and LeBlanc [20] for comparative male-female anatomy). Gonadal status of gynandromorphic individuals could not be determined. Tissue slices, prepared for histological analyses, consistently shattered presumably due to the interfering effects of the carapace/exoskeleton. However, some gynandromorphic animals produced viable offspring indicating the presence of functional ovaries (note embryos in the brood chamber of the gynandromorphic daphnid in Fig. 2C). The incidence of gynandromorphism among 5,710 offspring born to daphnids exposed to 48-50 $\mu \mathrm{g} / 1$ methyl farnesaote was $0.14 \%$. Sufficient numbers of offspring were evaluated from the methyl farnesoate treatment levels less than $48 \mu \mathrm{g} / 1(13,190)$ and greater than $50 \mu \mathrm{g} / 1$ $(10,113)$ to conclude that the incidence of gynandromorphism amongst these treatments was comparable to control daphnids (Fig 1A). The gynandromorphic phenotype is thus induced by methyl farnesoate but only within a tightly-defined concentration range.
Figure 1. Incidence of gynandromorphic offspring produced among maternal daphnids exposed to various concentrations of methyl farnesoate at $20^{\circ} \mathrm{C}$ (panel A) and $30^{\circ} \mathrm{C}$ (panel B). Panel A: Results from exposure to ranges of methyl farnesoate concentrations are presented to provide sufficient numbers of offspring per treatment to detect low incidences of gynandromorphism. Between 3,323 and 9,183 neonates were examined at each treatment level. Panel B: Maternal daphnids (5 per treatment level) were exposed to the indicated concentration of hormone and elevated temperature for $24 \mathrm{hrs}$ during ovarian oocyte maturation. The incidence of gynandromorphic offspring was based upon the total offspring examined at each treatment level (between 68 and 205 neonates per treatment).



Temperature promotes the gynandromorphic phenotype

We hypothesized that elevated temperatures could promote the appearance of the gynandromorphic phenotype as it promotes the juvenoid-regulated color phenotype of Manduca [15]. Exposure to methyl farnesoate at $30^{\circ} \mathrm{C}$ resulted in a 46 -fold increase in the maximum incidence of the gynandromorphic phenotype over the incidence observed with methyl farnesoate at $20^{\circ} \mathrm{C}$ (Fig. 1). Gynandromorphic individuals were produced at all methyl farnesoate concentrations evaluated at $30^{\circ} \mathrm{C}$ with an inverse relationship between methyl farnesoate exposure concentrations and incidence of gynandromorphism (Fig. 1B). No gynandromorphic offspring were produced among maternal organisms subjected only to elevated temperature. Thus, elevated temperature does promote the methyl farnesoate-dependent gynandromorphic phenotype. 
Figure 2. Female (panel A), male (panel B), and gynandromorphic (panel C) D. magna. Differentiating sex characteristics include the pair of minute first antennae (FA) of the females, the elongated FA of the males. Gynandromorphic individuals possessed an elongated FA partnered with a diminutive antenna. The female-like diminutive FA is obscured by the male-like elongated FA in the micrograph. The bivalved-like carapace of the female has two uniform, symmetrical edges (CE). Both CEs of the male are asymmetrical and are edged by setae. The gynandromorphic daphnid has one female-like symmetrical CE and one malelike asymmetrical CE.



Some insecticides induce the gynandromorphic phenotype

Some members of the phenoxyphenoxy insecticide family can mimic the action of methyl farnesoate and stimulate male-sex determination [14,21,22,24,25]. Experiments were therefore conducted to determine whether these environmental chemicals might also induce the gynandromorphic phenotype. Maternal daphnids were exposed to various concentrations of the phenoxyphenoxy insecticide pyriproxyfen at both 20 and $30^{\circ} \mathrm{C}$ and the production of gynandromorphic offspring was evaluated. At $20^{\circ} \mathrm{C}$, pyriproxyfen stimulated the production of gynandromorphic off- spring with a frequency comparable to that observed with methyl farnesoate though at 1000 -fold lower exposure concentrations $(0.08 \%$ incidence of gynandromorphism at $0.10 \mu \mathrm{g} / 1$ pyriproxyfen) (Fig. 3A). This high potency of pyriproxyfen is consistent with its high potency in stimulating male sex determination [21]. As observed with methyl farnesoate, intermediate concentrations of pyriproxyfen stimulated the production of gynandromorphic offspring while concentrations below and above these concentrations had no discernible effect.

Elevated temperature $\left(30^{\circ} \mathrm{C}\right)$ significantly increased the incidence of gynandromorphic offspring that was associated with pyriproxyfen exposure (Fig. 3B). The maximum incidence of gynandromorphism occurred among daphnids exposed to $0.20 \mu \mathrm{g} / 1$ pyriproxyfen $(5.5 \%)$ and was 37 -fold greater than the maximum incidence of gynandromorphism observed at $20^{\circ} \mathrm{C}$. Thus, elevated temperature also increased the expression of the gynandromorphic phenotype that was associated with exposure to the environmental chemical pyriproxyfen.

Table 2 Gynandromorphic individuals among neonates categorized by the dominant sex of the brood from which they originated $(<10 \%$ : broods dominated by females; 10 $90 \%$ : mixed male/female broods; $>90 \%$ : broods dominated by males). The incidence of gynandromorphic individuals was significantly different among categories $(\mathrm{P}<0.01)$.

\begin{tabular}{|c|c|c|}
\hline $\begin{array}{c}\text { Male constituency } \\
\text { of broods }(\%)\end{array}$ & $\begin{array}{c}\text { Number of gynandro- } \\
\text { morphic } \\
\text { neonates }\end{array}$ & $\begin{array}{c}\text { Total number of } \\
\text { neonates }\end{array}$ \\
\hline$<10$ & 1 & 15,533 \\
\hline $10-90$ & 11 & 31,464 \\
$>90$ & 0 & 18,122 \\
\hline
\end{tabular}

The gynandromorphic phenotype occurs among mixedsex broods

At low levels of methyl farnesoate, maternal daphnids produce only female offspring; while, at high concentrations maternal daphnids produce only males resulting in a sigmoidal concentration-response relationship (Fig. 4). However, the relationship between hormone level and gynandromorphism was bell shaped. The right half of the curve was revealed in the elevated temperature experiments with methyl farnesoate (Fig. 1B) and the entire curve was depicted in the elevated temperature experiments with pyriproxyfen (Fig. 3B). The shape of this concentration-response relationship suggests that gynandromorphism is likely to occur at hormone concentrations that stimulate the production of broods of offspring that contain a mix of males and females. This possibility was tested by evaluating 65,119 neonatal daphnids produced under the various conditions described in Table 1. Gynandromorphic individuals were identified and categorized as originating from broods of predominantly female offspring $(<10 \%$ males), broods of predominantly male offspring (>90\% male), or mixed broods (10-90\% male). Among these treatments, male offspring were produced only in response to methyl farnesoate, juvenile hormone, and the two juvenile hormone analogs (methoprene, pyriproxyfen). Gynandromorphs were produced among animals treated with methyl farnesoate and pyriproxyfen. All but one gynandromorphic animal originated from mixed male/female broods (Table 2). 
In experiments specifically involving methyl farnesoate exposure, all gynandromorphic animals were produced within the range of concentrations that produced mix-sex broods (Fig. 4). Comparable distributions in gynandromorphism were observed among the experiments performed with pyriproxyfen. These results confirm that gynandromorphism is stimulated by concentrations of sex determining hormone when present at intermediate levels that cause the production of mixed-sex broods of offspring.

Figure 3. Incidence of gynandromorphic offspring produced among maternal daphnids exposed to various concentrations of pyriproxyfen at $20^{\circ} \mathrm{C}$ (panel A) and $30^{\circ} \mathrm{C}$ (panel B). Panel A: Results from exposure to ranges of pyriproxyfen concentrations are presented to provide sufficient numbers of offspring per treatment to detect low incidences of gynandromorphism. Between 881 and 3605 neonates were examined at each treatment level. Panel B: Maternal daphnids ( 5 per treatment level) were treated with the indicated concentration of insecticide and elevated temperature for $24 \mathrm{hrs}$ during ovarian oocyte maturation. Between 143 and 204 neonates were examined at each treatment level.

Figure 4. Percentage males in broods of offspring produced by maternal daphnids exposed to concentrations of methyl farnesoate. Dashed lines demarcate the methyl farnesoate levels that produced: A) only female offspring, B) mixed-sex broods, and C) only males. The asterisk denotes the methyl farnesoate level at which gynandromorphic offspring were produced. Experiments were performed at $20^{\circ} \mathrm{C}$.

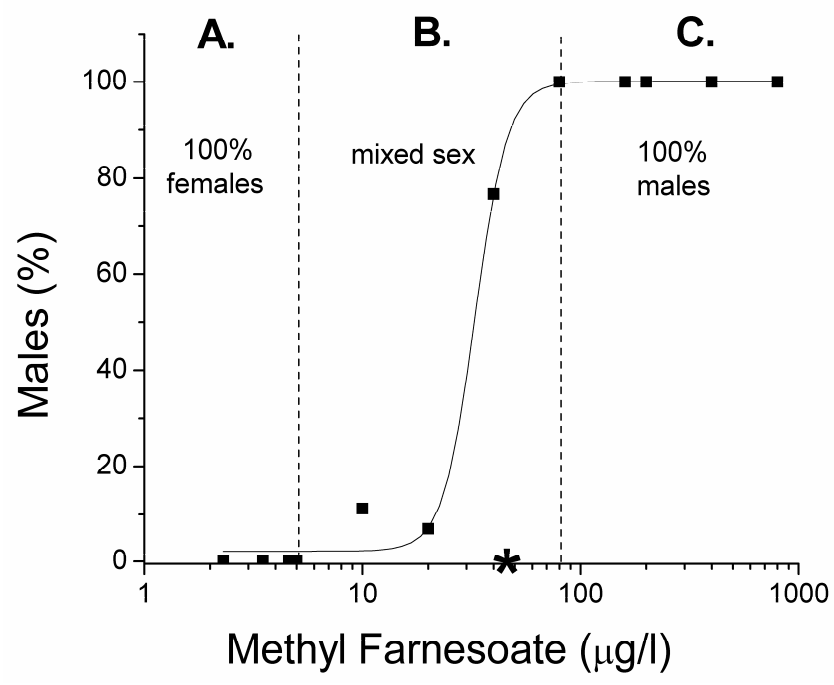

Elevated temperature interferes with male sex determination

Elevated temperature stimulated the production of gynandromorphic offspring in the presence of male sex-determining hormones. This implies that the elevated temperature interfered with the hormonal sexdetermining signal. If so, then elevated temperature should also reduce the number of male offspring produced by this hormonal signal. Maternal daphnids exposed to concentrations of methyl farnesoate at $30^{\circ} \mathrm{C}$ produced broods containing significantly $(p=0.01)$ fewer males than did similarly-treated daphnids at $20^{\circ} \mathrm{C}$ (Fig. 5A). This reduction in male offspring associated with elevated temperature was
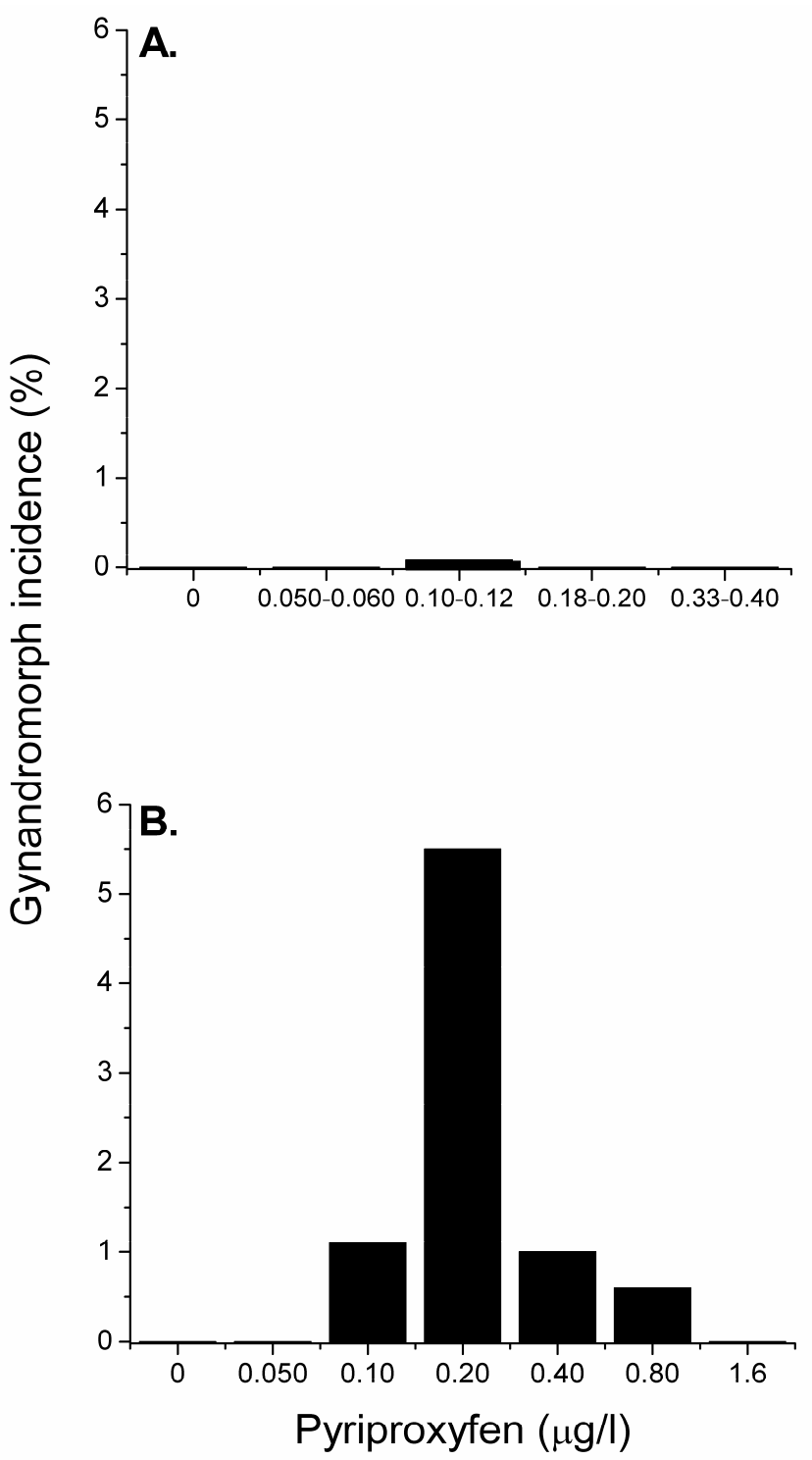

also evident $(p=0.04)$ with pyriproxyfen treatment (Fig. 5B). These results confirm that elevated temperatures compromise the sex-determining signaling pathway resulting in less male-sex determination commensurate with an increase in sexually ambiguous individuals.

\section{Discussion}

Methyl farnesoate is a terpenoid compound that is emerging as a major morphogen in crustaceans. The function of methyl farnesoate in crustaceans parallels those of retinoids in vertebrates and juvenoids in insects. For example, all contribute in some capacity to sex determination. Juvenoids function as sex determinants in some insects (e.g., aphids) where a high juvenoid titer results in the production of female offspring [26]. Retinoids dictate the sex-specific fate of germ cells in mice where high retinoic acid orchestrates progression of the germ cells to oocytes, while in the absence of retinoid acid, the germ cells develop into sperm [27]. High methyl farnesoate levels program mitotic eggs resulting from parthenogenesis in daphnids to develop into male offspring while in the absence of methyl farnesoate these eggs develop into females $[13,14]$. Such commonality in structure and function demonstrates that terpenoid hormones play a pivotal role in the development of sex as a reproductive strategy. 
Figure 5. Percentage male offspring in broods produced by maternal daphnids exposed to concentrations of methyl farnesoate (A) or pyriproxyfen (B) at $20^{\circ} \mathrm{C}$ (squares) or $30^{\circ} \mathrm{C}$ (circles). Data represent the mean value derived from five maternal daphnids. The incidence of male offspring was significantly $(p<0.05)$ reduced with either compound at $30^{\circ} \mathrm{C}$ as compared to the comparable treatments at $20^{\circ} \mathrm{C}$ (Student's paired $t$ test with arcsine proportion transformed data). Treatment levels in which $0 \%$ males or $100 \%$ males were observed at both temperatures (i.e., extreme low or high treatment levels) were not used in the statistical analyses.



Methyl farnesoate typically acts as an on-off switch in sex determination of daphnids. Maternal females produce broods of all-female offspring in the presence of low methyl farnesoate levels (Fig. 4). The production of all-female offspring is the norm for daphnid populations existing under conditions of abundant resources since an all female population coupled with asexual reproduction provides for rapid population growth [28]. However, in response to environmental stimuli that signal the approach of less hospitable conditions (e.g, decreasing photoperiod signaling the approach of winter, reduced food availability indication exploitation of resources or adverse environmental change), the male sex-determining program is initiated resulting in the production of broods of male offspring. Field populations typically produce all-male broods under this scenario [29,30]. The introduction of males into the population along with the subsequent production of meiotic eggs that require fertilization to develop provides the opportunity for genetic recombination. Sexual reproduction favors the purging of deleterious mutations from the gene pool [31]. Fertilized eggs typically enter a state of diapause through which the population can survive the inhospitable conditions [32]. Finally, fertilized, diapause eggs are typically encased in hydrophobic ephippium which renders the eggs subject to dispersal and colonization of new environments [28]. We demonstrate here that methyl farnesoate does not necessarily function as an on-off switch but, at intermediate levels, can result in both mixed-sex broods and gynandromorphic individuals in these broods. Gynandromorphism confers no obvious fitness advantage. However, the development of gynandromorphic daphnids may provide insight into the evolution of hermaphroditism, the identification of the signaling molecules that contribute to the development of hermaphroditic phenotypes, and the regulatory processes that orchestrate the development of hermaphrodites.

Bilateral gynandromorphism in crustaceans has historically been attributed to the loss or damage of a sex chromosome in one member of the cell pair resulting from the first embryonic cleavage [33]. As a result, these two cells, containing different sex blueprints, develop bilaterally into a gynandromorphic individual. We are aware of no evidence of sex chromosomes in daphnids [34] and, clearly, sex is programmed hormonally in these organisms. However, sex determination occurs late in ovarian oocyte maturation [13] which coincides with the time of the first embryonic cleavage [32]. Sex programming likely occurs prior to the first cell division so the sex blueprint is subsequently carried to both daughter cells. Elevated temperature may disrupt the timing of sex determination such that the sex-determining signals are received by some embryos after the first cell division. Signaling to only one of the daughter cells at this time would result in bilateral gynandromorphism.

Gynandromorphs are normally rare in field populations of crustaceans with incidences of normally $<1 \%$ [8]. We estimate the incidence of gynandromorphs in asexual D.magna populations at $<0.01$ $\%$ due to the low level of sex-determining hormone in individuals of these populations. The incidence of gynandromorphs increases to $\sim 0.1 \%$ among individuals of a population producing "sex-intermediate" levels of sex-determining hormone. However, in combination with elevated temperature, this incidence can increase $\sim 50$-fold. Mitchell [35] reported the occurrence of gynandromorphic offspring as a consequence of rearing daphnids at $30^{\circ} \mathrm{C}$. While, these organisms were not treated with sexdetermining hormone, it is likely that endogenous levels of hormone in the maternal daphnids were close to the threshold level required for male-sex determination among offspring since a low incidence of male offspring was noted along with the gynandromorphic offspring.

The mechanism by which elevated temperature promotes the hormone-induced gynandromorphic phenotype is not known. However, elevated levels of the protein HSP90 have been shown to suppress nuclear receptor function by interfering with the DNAbinding capacity of the receptor [36]. HSP90 is in- 
duced in daphnids by elevated temperatures as well as exposure to some chemicals $[37,38]$. Elevated temperatures may enhance the gynandromorphic phenotype by interfering with the ligand-dependent activation of the methyl farnesoate receptor resulting in compromised methyl farnesoate signaling of sex determination. Alternatively, elevated temperature might hasten the timing of embryonic cell division such that the window of sex determination crosses over into the the two-cell stage of the embryo with some low frequency of differential sex determination occurring between the two daughter cells.

Phenoxyphenoxy-based insecticides, such as pyriproxyfen, can mimic the action of methyl farnesoate to cause gynandromorphism. Pyriproxyfen is applied to insect breeding sites, including wetlands and livestock enclosures, to control mosquitoes, midges, flies, and beetles [39]. Pyriproxyfen is relatively long-lived in soil and water with measured half-lives ranging from 2 weeks to 2 months [40]. Using prediction models, the US Environmental Protection Agency estimates that prescribed usage rates for pyriproxyfen can result in long-term average concentrations approximating $0.40 \mu \mathrm{g} / 1$ in surface waters [40]. This concentration of pyriproxyfen and likely other structurally and functionally-related insecticides [22], in conjunction with elevated water temperatures associated with normal seasonality or longterm climate change, could be responsible for gynandromorphic conditions in some species.

Gynandromorphic individuals in field populations have been reported among various groups of organisms including crustaceans [8], molluscs [41], insects [42], spiders [43], ticks [44], frogs [45], and fishes [46]. Intersex in molluscs is most often the consequence of exposure to the environmental contaminant tributyltin [47]. Intersex frogs have been associated with the herbicide atrazine [48]. Organochlorine insecticides and other estrogenic contaminants are often implicated as the cause of intersex conditions in fish [49]. To this list of environmental causes of intersex must be added the induction of bilateral gynandromorphism by phenoxyphenoxy insecticides in some crustaceans. While the incidence of gynandromorphism in field populations of crustaceans might not attain a magnitude that would prove detrimental, its detection may serve as a biomarker of exposure to this specific class of environmental contaminant.

\section{Conflict of Interests}

The authors declare no conflict of interests.

\section{Acknowledgement}

This study was support by US Environmental Protection Agency Science to Achieve Results grants RD-83130001 and RD-83273901.

\section{References}

1. Land MF, Geer PJ, Bonzek CF, Austin HM. Juvenile finfish and blue crab stock assessment program bottom trawl survey annual data summary series, report 124 vol 1994. Gloucester Point, VA, USA: Virginia Institute of Marine Science. 1995.

2. Land MF, Geer PJ, Bonzek CF, Austin HM. Juvenile finfish and blue crab stock assessment program York River random bottom trawl survey data summary report, report 124 vol R19891990. Gloucester Point, VA, USA: Virginia Institute of Marine Science. 1996
3. Van Patten P. A decapod crustacean, who-dun-it? Wrack Lines Magazine 2004;2:3-16.

4. Taylor DM, Okeffe PG, Fitzpatrick C. A snow crab, Chionoecetes opilio (Decapod, Majidae), fishery collapse in Newfoundland. Fishery Bull. 1994;92:412-419.

5. Orensanz JM, Armstrong J, Armstrong D, Hilborn R. Crustacean resources are vulnerable to serial depletion - the multifaceted decline of crab and shrimp fisheries in the Greater Gulf of Alaska. Rev. Fish Biol. Fisheries 1998;8:117-176.

6. Stockhausen WT, Lipcius RN. Simulated effects of seagrass loss and restoration on settlement and recruitment of blue crab postlarvae and juveniles in the York River, Chesapeake Bay. Bull. Mar. Science 2003;72:409-422.

7. Selberg CD, Eby LA, Crowder LB. Hypoxia in the Neuse River estuary: Responses of blue crabs and crabbers. North Amer. J. Fish. Manag. 2001;21:358-366.

8. LeBlanc GA. Crustacean endocrine toxicology: A review. Ecotoxicology; in press.

9. Ford AT, Fernandes TF, Read PA, Robinson CD, Davies IM. The costs of intersexuality: a crustacean perspective. Mar. Biol. 2004;145:951-957.

10. Ford AT, Rodgers-Gray TP, Davies IM, et al. Abnormal gonadal morphology in intersex, Echinogammarus marinus (Amphipoda): a possible cause of reduced fecundity? Mar. Biol. 2005;147:913-918.

11. Olmstead AW, LeBlanc GA. Temporal and quantitative changes in sexual reprodutive cycling of the cladoceran Daphnia magna by a juvenile hormone analog. J. Exp. Zool. 2001;290:148-155.

12. Naylor C, Adams J, Greenwood PJ. Variation in sex determination in natural populations of a shrimp. J. Evol. Biol. 1988;1:355368.

13. Olmstead AW, LeBlanc GA. The juvenoid hormone methyl farnesoate is a sex determinant in the crustacean Daphnia magna. J. Exp. Zool. 2002;293:736-739.

14. Tatarazako N, Oda S, Watanabe H, Morita M, Iguchi T. Juvenile hormone agonists affect the occurrence of male Daphnia. Chemosphere 2003;53:827-833.

15. Suzuki Y, Nijhout HF. Evolution of a polyphenism by genetic accomodation. Science 2006;311:650-652.

16. Laufer H, Ahl JSB, Sagi A. The role of juvenile hormones in crustacean reproduction. Amer. Zool. 1993;33:365-374.

17. Laufer H, Biggers WJ. Unifying concepts learned from methyl farnesoate for invertebrate reproduction and post-embryonic development. Amer. Zool. 2001;41:442-457.

18. Baldwin WS, LeBlanc GA. Identification of multiple steroid hydroxylases in Daphnia magna and their modulation by xenobiotics. Environ. Toxicol. Chem. 1994;13:1013-1021.

19. Nichols HW. Growth media - Freshwater. In: Stein J, ed. Handbook of Phycological Methods: Culture Methods and Growth Measurements. London: University Press, 1973:7-24.

20. Olmstead AW, LeBlanc GA. Effects of endocrine-active chemicals on the development of sex characteristics of Daphnia magna. Environ. Toxicol. Chem. 2000;19:2107-2113.

21. Olmstead AW, LeBlanc GA. Insecticidal juvenile hormone analogs stimulate the production of male offspring in the crustacean Daphnia magna. Environ. Health Perspect. 2003;111:919924.

22. Wang HY, Olmstead AW, Li H, LeBlanc GA. The screening of chemicals for juvenoid-related endocrine activity using the water flea Daphnia magna. Aquatic Toxicol. 2005;74:193-204.

23. Zar JH. Biostatistical Analysis. Upper Saddle River, NJ: Prentice-Hall, 1996.

24. Oda S, Tatarazako N, Watanabe H, Moriata M, Iguchi T. Production of male neonates in four cladoceran species exposed to a juvenile hormone analog, fenoxycarb. Chemosphere 2005;60:74-78.

25. Oda S, Tatarazako N, Watanabe H, Morita M, Iguchi T. Production of male neonates in Daphnia magna (Cladocera, Crustacea) exposed to juvenile hormones and their analogs. Chemosphere 2005;61:1168-1174

26. Hales DF, Mittler TE. Chromosomal sex determination in 
aphids controlled by juvenile hormone. Genome 1987;29:107109.

27. Bowles J, Knight D, Smith C, et al. Retinoid signaling determines germ cell fate in mice. Science 2006;312:596-600.

28. Hebert PDN. The population biology of Daphnia (Crustacea, Daphnidae). Biol. Rev. 1978;53:387-426.

29. Barker DM, Hebert PDN. Secondary sex ratio of the cyclic parthenogen Daphnia magna (Crustacea: Cladocera) in the Canadian Arctic. Can. J. Zool. 1986;64:1137-1143.

30. Hobaek A, Larsson P. Sex determination in Daphnia magna. Ecology 1990;71:2255-2268.

31. Paland S, Lynch M. Transitions to asexuality result in excess amino acid substitutions. Science 2006;311:990-992.

32. Smith DG. Pennak's Freshwater Invertebrates of the United States. fourth ed. New York: John Wiley \& Sons, 2001.

33. Farmer AS. A bilateral gynandromorph of Nephrops norvegicus (Decapoda: Nephropidae). Mar. Biol. 1972;15:344-349.

34. Lecher P, Defaye D, Noel P. Chromosomes and nuclear DNA of Crustacea. Invert. Reprod. Develop. 1995;27:85-114.

35. Mitchell SE. Intersex and male development in Daphnia magna. Hydrobiologia 2001;442:145-156.

36. Pratt $W B$, Toft $D O$. Steroid receptor interaction with heat shock protein and immunophilin chaperones. Endocrin. Rev. 1997;18:306-360.

37. Bond JA, Gonzalez CRM, Bradley BP. Age-dependent expression of proteins in the cladoceran Daphnia magna under normal and heat-stress conditions. Comp. Biochem. Physiol. 1993;106B:913-917.

38. Soetaert A, Moens LN, Van der Ven K, et al. Molecular impact of propiconazole on Daphnia magna using a reproductionrelated cDNA array. Comp. Biochem. Physiol. 2006;142C:66-76.

39. Pedigo LP, Rice ME. Entomology and Pest Management. fifth ed. Upper Saddle River, NJ: Pearson-Prentice Hall, 2006.

40. USEPA. Pyriproxyfen; pesticide tolerance. Fed. Register 2002;67:55150-55160.

41. Matthiessen P, Reynoldson T, Billinghurst Z, et al. Field assessment for endocrine disruption in invertebrates. In: deFur PL, Crane M, Ingersoll C, Tattersfield L, eds. Endocrine Disruption in Invertebrates: Endocrinology, Testing, and Assessment. Pensacola FL: SETAC Press, 1999:199-270.

42. Ishizawa N. A gynandromorphic specimen of Sympetrum frequens Selys. Tombo 1990;33:37-39.

43. Stratton GE. A gynandromorphic Schizocosa (Araneae, Lycosidae). J. Arachn. 1995;23:130-133.

44. Labruna MB, Riberiro AF, Cruz MV, Camargo LMA, Camargo EP. Gynandromorphism in Amblyomma cajennense and Rhipicephalus sanguineus (Acari: Ixodidae). J. Parasit. 2002;88:810-811.

45. Reeder AL, Foley GL, Nichols DK, et al. Forms and prevalence of intersexuality, and effects of environmental contaminants on sexuality in cricket frogs (Acris crepitans). Environ. Health Perspect. 1998;106:261-266.

46. De Metrio G, Corrieroa A, Desantisa S, et al. Evidence of a high percentage of intersex in the Mediterranean swordfish (Xiphias gladius L). Mar. Pollut. Bull. 2003;46:358-361.

47. Matthiessen P, Gibbs PE. Critical appraisal of the evidence for tributyltin-mediated endocrine disruption in mollusks. Environ. Toxicol. Chem. 1999;17:37-43.

48. Hayes TB, Collins A, Mendoza M, Noriega N, Stuart AA, Vonk A. Hermaphroditic, demasculinized frogs exposed to the herbicide atrazine at low ecologically relevant doses. Proc. Nat. Acad. Sci. USA 2002;99:5476-5480.

49. Matthiessen P. Endocrine disruption in marine fish. Pure Appl. Chem. 2003;75:2249-2261. 